\title{
Inattention in Financial Markets
}

\section{Srikant Marakani*}

Department of Economics and Finance, City University of Hong Kong

The role of inattention in financial markets and asset pricing has received significant attention in the last few years. Its importance was brought home to me particularly forcefully on reading, in recent headline news, that the average stock holding time is now just twenty two seconds. Since humans, including even professional traders, are physically incapable of paying continuous attention to news and financial markets at these small time scales, it follows that inattention must pay a vital role in explaining at least the short term movements in the prices of these stocks and assets in general. While the equivalent conclusion for longer time scales does not follow in such an obvious manner, the recent work of Jagannathan and Wang [1] and Jagannathan et al. [2] provide strong evidence that it is important even in time scales of a year or more. Rational inattention is closely related, but distinct, from the concept of transaction costs. While transaction costs are usually the same or similar enough for all investors and are easily measurable, the costs of paying attention are markedly different for different investors and are effectively unobservable in practice. This makes the investigation of this subject challenging both theoretically and empirically. The theoretical foundations for the study of inattention and, in particular, rational inattention were laid in the pioneering work $^{1}$ of Sims [3,4] and Moscarini [5]. These studies represent some of the many fruitful interactions between information theory and finance. In particular, Sim's idea of modeling rational inattention in terms of postulating a finite processing capacity (in the sense of Shannon) provides an elegant framework for dealing with rational inattention. More recent studies which have significantly built on this work from the point of view of the investors ${ }^{2}$ are those of Sims [6], Ricardo [7], Huang and Liu [8], Bacchetta and Eric [9] and Abel et al. [10]. They found, in general, that rational inattention can have a great impact on consumption, portfolio choice and asset prices and that they can explain certain asset pricing puzzles such as the forward discount puzzle in foreign currency markets. As with the study of general transaction costs, the models studied in this area of research are chosen partially on the basis of tractability as generic models are, in general, unsolvable. Hence, from a theoretical point of view, progress still needs to be made and this could provide one possible direction for future research. A more pressing gap in the research agenda for this subject, the lack of time varying attention costs, becomes apparent when the important empirical results of Jagannathan and Wang [1] and Jagannathan et al. [2] are taken into account. They show that, in contrast to conventional wisdom, the consumption CAPM can explain the cross section of stock returns but only if consumption and stock returns are measured from the end of one tax year to the next. The mechanism proposed in the above studies is based on the differing costs of information acquisition or of paying attention to the stock market over the year. At the end of the tax year, investors are forced to study their portfolios and realign them in order to take advantage of tax code provisions. Since this analysis is necessary for other reasons, the marginal cost of paying attention to the market in this period is very low and investors are highly likely to pay attention and process more information during this period. While highly plausible and intuitive, comprehensive theoretical

'I apologize to the many authors whose important work I have not cited due to the obvious space constraints.

${ }^{2}$ Mackowiak and Wiederholt (2007) is an interesting application of the concept in relation to firms rather than financial investors. analysis of this hypothesis still remains to be done as solutions for infinite horizon inattention models with time varying attention costs are difficult to obtain. The costs of paying attention to the financial market for average investors also need to be empirically investigated so as to guide theoretical research into this area. Most of the interesting work in this area such as that of Lusardi [11,12], Ameriks et al. [13], Lusardi and Olivia [14] is not directed at addressing this precise issue but only deals with it in a more general context. Hence, a gap does exist in this literature and it will be interesting to see research done to address it. I will end this editorial with the observation that analyzing the costs of paying attention provides a way of incorporating the complications of human behavior into finance in a manner very distinct from conventional behavioral finance. It provides an approach where it is the human limitations and costs of processing information are the key ingredients rather than irrationality. This provides strong constraints and a framework for incorporating human behavior into finance which conventional behavioral finance sometimes lacks. This makes me eagerly look forward to the results of research progress in this area.

\section{References}

1. Jagannathan $R$, Wang $Y(2007)$ Lazy investors, discretionary consumption, and the cross-section of stock returns. J Financ 62: 1623-1661.

2. Jagannathan R, Marakani S, Takehara H, Wang Y (2011) Calendar Cycles Infrequent Decisions and the Cross-Section of Stock Returns. Manage Sci.

3. Sims CA (2003) Implications of rational inattention. J Monet Econ 50: 665-690.

4. Sims CA(2005) Rational inattention: a research agenda. Deutsche Bundesbank

5. Moscarini G (2004) Limited information capacity as a source of inertia. J Econ Dynam Control 28: 2003-2035.

6. Sims CA (2006) Rational inattention: Beyond the linear-quadratic case. The Amer econ rev 96: 158-163.

7. Ricardo R (2006) Inattentive consumers, J Monet Econ 53: 1761-1800.

8. Huang L, Liu H (2007) Rational inattention and portfolio selection, The Journal of Finance 62: 1999-2040.

9. Bacchetta P, Eric van W (2005) Rational inattention: A solution to the forward discount puzzle. NBER 11633.

10. Abel AB, Eberly JC, Panageas S (2009) Optimal Inattention to the Stock Market with Information Costs and Transactions Costs. NBER 5010.

11. Lusardi A (1999) Information, expectations, and savings for retirement, in

*Corresponding author: Srikant Marakani, Department of Economics and Finance, City University of Hong Kong, Hong Kong, Tel: 852-3442-8450; Fax: 8523442-0195; E-mail: smarakan@cityu.edu.hk

Received January 16, 2012; Accepted February 17, 2012; Published February 20, 2012

Citation: Marakani S (2012) Inattention in Financial Markets. J Bus \& Fin Aff 1:e108. doi:10.4172/bsfa.1000e108

Copyright: @ 2012 Marakani S. This is an open-access article distributed under the terms of the Creative Commons Attribution License, which permits unrestricted use, distribution, and reproduction in any medium, provided the original author and source are credited. 
Behavioral Dimensions of Retirement Economics. Brookings Institution Press and Russell Sage Foundation Washington, DC 81-115.

12. Lusardi $A$ (2003) Planning and savings for retirement.

13. Ameriks J, Caplin A, Leahy J (2003) Wealth accumulation and the propensity to plan. Quart J Econ 118: 1007-1047.
14. Lusardi A, Olivia AM (2009) How ordinary consumers make complex economic decisions: Financial literacy and retirement readiness.

15. Mackowiak B, Wiederholt M (2007) Optimal sticky prices under rationa inattention, CEPR Discussion Paper DP6243. 